\title{
Analysing the Coupled Effects of Compressive and Diffusion Induced Stresses on the Nucleation and Propagation of Circular Coating Blisters in the Presence of Micro-cracks
}

\author{
M. H. Nazir ${ }^{1 *}$, Z. A. Khan ${ }^{1}$, K. Stokes ${ }^{2}$ \\ ${ }^{1}$ Bournemouth University \\ NanoCorr, Energy and Modelling (NCEM) Research Group \\ Faculty of Science and Technology, Bournemouth, UK ${ }^{1}$ \\ ${ }^{2}$ Defence Science and Technology Laboratory (DSTL), Ministry of Defence (MoD), Salisbury, UK
}

\begin{abstract}
This paper presents the delamination of coating with micro-cracks under compressive residual stress coupled with diffusion induced stress. Micro-cracks in coating provide a passage for corrosive species towards the coating-substrate interface which in turn produces diffusion induced stress in the coating. Micro-cracks contract gradually with increasing compressive residual stress in coating due to thermal expansion mismatch which blocks the species diffusion towards the interface. This behaviour reduces the diffusion induced stress in the coating while the compressive residual stress increases. With further increase in compressive residual stress, micro-cracks reach to the point, where they cannot be constricted any further and a high compressive residual stress causes the coating to buckle away from the substrate resulting in delamination and therefore initiating blistering. Blistering causes the contracted micro-cracks to wide open again which increases diffusion induced stress along with high compressive residual stress. The high resultant stress in coating causes the blister to propagate in an axis-symmetric circular pattern. A two-part theoretical approach has been utilised coupling the thermodynamic concepts with the mechanics concepts. The thermodynamic concepts involve the corrosive species transportation through micro-cracks under increasing compression, eventually causing blistering, while the fracture mechanics concepts are used to treat the blister growth as circular defect propagation. The influences of moduli ratio, thickness ratio, thermal mismatch ratio, poisson's ratio and interface roughness on blister growth are discussed. Experiment is reported for blistering to allow visualisation of interface and to permit coupled (diffusion and residual) stresses in the coating over a full range of interest. The predictions from model show excellent, quantitative agreement with the experimental results.
\end{abstract}

Keyword: Interfaces; Films; Coatings; Delamination; Blister; Micro-crack; Compressive residual stress; Diffusion induced stress

\section{Introduction}

Protective coatings tend to prevent the effects of physical and chemical attack on the substrate. However, in some circumstances this attack is promoted, rather than hindered, and this results in the delamination of coatings [1]. There are several causes of coating delamination such as micro-defects at the coating substrate interface and micro-cracks in coatings $[2,3]$. Most coating systems suffer deterioration due to the presence of coating microcracks. These micro-cracks are produced at the time of fabrication or are very likely to have been caused by the difference in coefficients of thermal expansion of coating and the steel substrate. These micro-cracks may act as pathways for corrosive agents to diffuse through the coating barrier, which may result in the loss of adhesion between coating and substrate thus causing delamination [4]. Stress corrosion cracking (SCC), due to microcracks opening in a corrosive environment, results when the materials are subjected to tensile residual stress in a corrosive environment [5-7]. Contrary to this, compressive residual stress causes the contraction of micro-cracks resulting in the inhibition of corrosion which proves beneficial for the control of SCC [8,9]. It is implied that the micro-cracks behaviour in materials correlate to the residual stresses in the materials. Along with the residual stress, the chemical stress (or diffusion induced stress) also influences the micro-cracks behaviour and

\footnotetext{
1* Mian Hammad Nazir; Phone No.: +44(0)7424926269; Email: hnazir@,bournemouth.ac.uk
} 
therefore, affects the stability and reliability of materials [10]. The behaviour of micro-cracks in coatings under the coupling effect of residual stress and diffusion induced stress can result in early failure of coatings due to delamination which is a conventional problem and is currently receiving greater attention from the coatings industry [3].

For residual stress analysis, vast literature has been available since the pioneering work of Stoney [11] on the formulation of stress variations derived from the experimental measurement of system curvature changes. Later on, based on Stoney formula various models have been developed [12-18] to address numerical computations of uniform residual strain in the coating. Recently, a model using computational techniques identified that the corrosion at the interface of coating and substrate is inhibited by compressive residual stress in coating due to the contraction of open corrosion paths in the coatings [19]. However, the model did not address the effects of the compressive residual stress over pre-existing structural micro-cracks in the coating and how compressive residual stress in coating may lead to complete delamination forming blisters. Hence the presented work contributes to significant knowledge creation in this theme.

Meanwhile, for diffusion induced stress various numerical models [20-26] were developed in previous decades after a series of studies on diffusion induced stress in the coating system. Many of these models were based on the pioneering work of Podstrigach [27]. In recent years, models using advanced computational methods involving diffusion induced stress have been developed [2, 28-30]. However, it is worth noting that the occurrence of the residual stress in the coating due to mismatch in thermal expansion cannot be neglected. Therefore, both the diffusivity and concentration of corrosive species will be enhanced by the hydrostatic stress [31]. Actually, the existing stress may speed up the diffusivity by opening the micro-cracks under tensile behaviour or hinder the diffusivity by constricting the micro-cracks under compressive behaviour.

When the thermal expansion of coating is greater than the substrate i.e. $\alpha_{c}>\alpha_{s}$, the positive temperature diversification $(\Delta \mathrm{T}>0)$ from its fabrication temperature will induce compressive residual stress in the coating [9, 32-35]. The pre-exiting micro-cracks in coating will gradually contract with increasing compressive residual stress on temperature rise. The increasing compressive residual stress will constrict the pathways for the diffusing corrosive species towards the interface. This will reduce the effect of diffusion induced stress in coating while the compressive residual stress will be high. To this point of rising $\Delta \mathrm{T}$, the direction of diffusion induced stress can be treated as opposite to that of the compressive stress gradient. With the further increase in compressive residual stress, the micro-cracks will constrict to the point where they cannot be constricted further and the coating will buckle away from the substrate under high compressive loading. Buckling will cause the tightly closed micro-cracks to wide open again, letting the diffusion of corrosive species. The buckling of coating from the substrate will form circular blister. At this point the direction of diffusion induced stress can be treated as similar to that of the compressive stress gradient. The high resultant stress in coating will cause the blister to propagate in an axis-symmetric circular pattern.

Pervious research has analysed [36-45] coating substrate system without the inclusion of micro-cracks. However, this research aims to analyse the coupling effects of residual and diffusion induced stresses on blister growth in the presence of coating micro-cracks. The analysis is performed within the framework of thermodynamics coupled with mechanics. The novelty within this research is the utilisation of two-part theoretical approach for circular blister nucleation and propagation incorporating the effects of coating microcracks, which has not been used in previous blistering models [46-52]. The combination of thermodynamics and mechanics approaches provides a novel technique to understand coating failures with micro-cracks. The diffusion concepts are used to model the transport of corrosive species through micro-cracks, under increasing compression, eventually causing blistering, while the fracture mechanics concepts are used to model the blister propagation as circular interfacial defect growth. The theoretical model is based on the experimental study which is conducted to analyse the key role that residual and diffusion induced stresses play in the nucleation and propagation of blisters in the presence of micro-cracks. The experiments validate the predications of theoretical model which are later highlighted in the simulation part. The predications of circular blister growth show excellent quantitative and qualitative agreement with the experiments. This research is significant in terms of wider industrial application both in static and dynamic load applications. 


\section{Experiment}

\subsection{Sample preparation and experimental setup}

A thin carbon steel (AISI-SAE-1020) substrate with thickness $\mathrm{s}=0.01 \mathrm{~cm}$ was used to prepare seven coated test samples with dimensions $15 \mathrm{~cm} \times 10 \mathrm{~cm}$ each. The chemical composition of the carbon steel is $0.18-0.23 \% \mathrm{C}$, $0.3-0.6 \% \mathrm{Mn}$, and balanced $\mathrm{Fe}$ [53]. The purpose of preparing seven test samples was to analyse cross sectional (by using six out of seven samples) and top view (by using remaining one sample) microscopic images during the experimental procedure. The cross sectional analysis is a destructive process and therefore one of six samples at a specific test condition was taken out of the experimental procedure every time for the cross sectional analysis. With such approach, it was possible to attain six distinct cross sectional images (one image for each sample of the six samples) at six different experimental conditions during the experimental procedure. The cross sectional analysis of six samples under the microscope was performed by using a magnification of 10 $\mathrm{x}$. The last remaining seventh sample was not required to be taken out of the experimental procedure every time for the top view surface analysis. Therefore the top view optical microscopic images by using a high resolution portable microscope with a resolution of $2 \mathrm{x}$ and $10 \mathrm{x}$ were obtained from the seventh sample under different conditions during the experimental procedure.

The coefficient of thermal expansion (CTE) and Young's modulus for the steel are $\alpha_{\mathrm{s}}=11.7 \times 10^{-6} \mathrm{~K}^{-1}$ and $\mathrm{E}_{\mathrm{s}}=$ $200 \mathrm{GPa}$ respectively [53]. Prior to coating deposition on steel samples, surface conditioning of steel sample was deployed by using polishing wheel with emery paper of 200 grit size. Post polishing, the conditioned samples were cleaned with a 35 min immersion into a constantly stirred solution of 50g/L Turco 4215 NC-LT. After completing this alkaline cleaning the samples were rinsed with deionized water and then air dried. Weight of the test samples was recorded to the nearest fifth significant figure and the steel samples were stored in a desiccator. Next, thin primer red oxide coating was applied on one side of the samples by using a conventional spraying gun at a temperature of $318 \mathrm{~K}\left(45^{\circ} \mathrm{C}\right)$. The thickness of the coating was $\mathrm{h}=20 \mu \mathrm{m}$. The reason for applying coating on one side of samples was to heat the uncoated side in a chamber, while testing the coated side of the samples against high temperature. The chemical composition of primer red oxide is: white spirit (10$30 \%$ ), low Aromatic white spirit (1-5\%), 2- Butanone Oxime $(<1 \%)$, Xylene and Mixed Isomers $(<0.1 \%)$ [54]. The coefficient of thermal expansion CTE $\left(\alpha_{\mathrm{c}}=21.6 \times 10^{-6} \mathrm{~K}^{-1}\right)$ and Young's modulus $\left(\mathrm{E}_{\mathrm{c}}=6.14 \mathrm{GPa}\right)$ for coating were measured by using thermomechanical analysis test according to the procedures of ASTM E831-14 and ASTM E2769 - 13 respectively. Coating was allowed to fully seal over a 24 hours period at $318 \mathrm{~K}$ before testing. The temperature $318 \mathrm{~K}$ is referred to as the fabrication temperature of coating-substrate system. For ex situ residual stress measurement of thin coatings during experimentation, optical sensing technique (KSA multibeam optical sensor) was deployed [55]. The residual stress measurement was performed by monitoring the substrate curvature with an array of parallel laser beams and a CCD detector. The diffusion rate of species towards the interface was monitored by using a three electrode electrochemical system which was then used to calculate the diffusion induced stress by using conventional formulation [56]. Cross sectional and top view images of test samples were recorded frequently in order to analyse the condition of coating in terms of coating micro-cracks and blister propagation.

The behaviour of various micro-cracks on each sample (which was taken out of the experimental procedure for the microscopic analyses) was observed at different data points on the sample by using microscope. The cross sectional images of micro-cracks which were taken at different data points on the sample showed that all microcracks corresponding to different data points on the sample presented similar behaviour. However, for the purpose of discussion, the cross sectional images of a single micro-crack from each sample at various conditions are presented in this paper. The cross sectional images were used to measure the aperture size of micro-cracks such that a criterion was identified in which the size of aperture was measured at a depth of $0.5 \mu \mathrm{m}$ from the surface of coating for all micro-cracks. 


\subsection{Accelerated testing procedure}

The experiment was designed to analyse the effect of compressive residual stress on the delamination of coating and its propagation in the presence of diffusion induced stress. All the seven samples were transferred from the temperature controlled unit where the samples were fully sealed over a 24 hours period at $318 \mathrm{~K}$ after their fabrication, to a corrosive atmosphere chamber such that the temperature of samples did not change from the fabrication temperature $(318 \mathrm{~K})$ during this transfer. This was achieved by transporting the samples inside a passive container with a well-maintained fabrication temperature. After transportation, the samples were then exposed to a corrosive environment inside the atmosphere chamber. The initial temperature of chamber was set at $318 \mathrm{~K}$ which is equal to the fabrication temperature of samples. The transport procedure with controlled temperature was adapted in order to avoid any temperature ramp of samples above the fabrication temperature $(318 \mathrm{~K})$. Inside the chamber, the electrolyte solution creating the fog was a 5 parts of sodium chloride in 95 parts of deionized water. All seven samples were positioned at a $60^{\circ}$ angle inside the chamber with the coated face downward, as to avoid the direct pathway for condensate in to the coating. Samples were mounted inside the chamber on a stage, with controllable temperature facility to adjust the temperature of mounted samples. This technique was adapted in order to slowly increase the temperature of samples to $358.15 \mathrm{~K}\left(85^{\circ} \mathrm{C}\right)$ from their fabrication temperature $(318 \mathrm{~K})$ at the same time when they were exposed to salt spray. The temperature was increased at the rate of $1 \mathrm{~K}$ for every 1 hour. During the temperature increase from $318 \mathrm{~K}$ to $358.15 \mathrm{~K}$, six cross sectional images, one image from each sample of six samples (which were specially dedicated for cross sectional analyses due to the destructive nature of cross sectional procedure) were obtained at six corresponding $\Delta \mathrm{T}$ values respectively i.e. $\Delta \mathrm{T}=1 \mathrm{~K}, 3 \mathrm{~K}, 10 \mathrm{~K}, 15 \mathrm{~K}, 25 \mathrm{~K}$ and $35 \mathrm{~K}$. For each $\Delta \mathrm{T}$ value, one out of six samples was taken out of the chamber and transported to the microscope for cross sectional examination. During the process of transport and analysis, the temperature of samples was strictly maintained to the value at which it was taken out of the chamber in order to avoid false results. Such procedure provided with six distinct cross sectional images at six various $\Delta \mathrm{T}$ values, as shown in fig. 1(a-f). Similarly, the top view microscopic images at six different $\Delta \mathrm{T}$ values (as above) were obtained from the single sample (which was specially dedicated for top view analysis) by using a high resolution portable microscope.

The increase in $\Delta \mathrm{T}>0$ from fabrication temperature $(318 \mathrm{~K})$ resulted in the increase of compressive residual stress in coating due to mismatch of CTE $\left(\alpha_{c}>\alpha_{s}\right)$ between coating and steel. $\Delta \mathrm{T}$ is given as [57]

\section{$\Delta \mathbf{T}=$ Final temperature - Fabrication temperature}

The diffusion of corrosive species through coating micro-cracks as a result of samples exposure in chamber induced diffusion stress in the coating along with compressive residual stress due temperature increase.

\subsection{Experimental observations}

When the samples are exposed to the diffusing species in an environmental chamber, the diffusion of species through pre-existing micro-cracks starts which in turn induces diffusion stress in the coating. At the same time, the temperature change $(\Delta T)$ induces residual stress in the coating. The concentration of diffusing species is controlled by the residual stress in the coating. The residual stress can either block the pathway of corrosive species (due to compressive behaviour when $\Delta \mathrm{T}>0$ ) by constricting the aperture of pre-existing micro-cracks or can open the pathway of corrosive species (due to tensile behaviour when $\Delta \mathrm{T}<0$ ) by exposing/opening the aperture of coating micro-cracks $[32,34,35,58]$. For the coating substrate system with pre-existing coating micro-cracks, the size of the micro-crack aperture is a linear function of residual stress due to mismatch strain between the coating and substrate and the bending moment introduced by diffusion. The experimental observations, based on diffusion and compressive residual stress in the coating were divided in to three regions as discussed below.

\subsubsection{Region 1}

At the initiation of experiment when the temperature was close to the fabrication temperature of coating substrate system i.e. $\Delta \mathrm{T}$ equal to $1 \mathrm{~K}$, the aperture size of micro-crack was $2.1 \mu \mathrm{m}$. This wide aperture provided 
the pathway for the diffusing species through the coating towards the interface as shown in fig. 1 (a). Therefore at the start of the experiment, concentration of the diffusing species was high but still not high enough to start the process of corrosion at the interface of coating and substrate as show in fig. 1 (a). Further with the increase in $\Delta \mathrm{T}$ to $3 \mathrm{~K}$, the aperture of micro-crack decreased slightly from $2.1 \mu \mathrm{m}$ to $1.3 \mu \mathrm{m}$ because of small rise in compressive residual stress in coating. At this stage, the concentration of diffusing species slightly reduced thus resulting in the small decrease in diffusion induced stress. The stress graphs for region 1 are also shown in fig. 2. In this region, due to overall high diffusion induced stress compared to small compressive residual stress, no significant blistering failure, due to delamination was observed, as shown in cross sectional image in fig. 1 (a-b) and top view image in fig. $3(\mathrm{a}-\mathrm{b})$. As the diffusion rate was initially high and then decreased slightly with respect to small increase in compressive residual stress, therefore, the direction of diffusion induced stress can be treated as opposite to that of the compressive stress gradient. Therefore, the elastic response of coating in region 1, which affected by the compressive residual stress $\sigma_{\mathrm{r}_{\mathrm{c}}}$ and diffusion induced stress $\sigma_{\mathrm{d}_{\mathrm{c}}}$ can be analysed in terms of the principle of linear superposition [59] as,

$$
\sigma=\sigma_{\mathbf{r}_{\mathrm{c}}}+\sigma_{\mathrm{d}_{\mathrm{c}}}
$$

Where, $\sigma$ is the resultant stress, coupling the effect of compressive residual stress $\sigma_{\mathrm{r}_{\mathrm{c}}}$ and diffusion induced stress $\sigma_{\mathrm{d}_{\mathrm{c}}}$. In this region, the diffusion induced stress can be treated as a major influential parameter in coating because of initial high diffusion rate while compressive residual stress can be treated as a minor parameter because of its low value. Diffusion induced stress $\sigma_{\mathrm{d}_{\mathrm{c}}}$ is represented in region 1 in fig. 2 as the only major influential parameter. Eq. 2 can now be modified in order to represent the diffusion induced stress as the major parameter.

$$
\sigma=\sigma_{\mathrm{r}_{\mathrm{c}}}+\sigma_{\mathrm{d}_{\mathrm{c}}} \approx \sigma_{\mathrm{d}_{\mathrm{c}}}
$$

\subsubsection{Region 2}

With the further increase in $\Delta \mathrm{T}$ to $10 \mathrm{~K}$, the compressive residual stress corresponding to increasing $\Delta \mathrm{T}$ also increased. The high compressive residual stress constricted the aperture of micro-crack to the size of $0.6 \mu \mathrm{m}$. The small sized aperture minimized the concentration of diffusing species which in turn reduced the effect of diffusion induced stress in the coating as shown in cross sectional image fig. 1(c) and top view image in fig. 3 (c). As $\Delta \mathrm{T}$ was further increased till $13 \mathrm{~K}$, the size of micro-crack aperture reduced to $0.07 \mu \mathrm{m}$ and reached to a point where it could not be constricted any further. At this point the high compressive residual stress initiated the buckling of coating from substrate at the interface as shown in the cross sectional image in fig. 1 (d) and top view image with visible tiny circular shaped blister in fig. 3 (d). The radius of the delaminated area at the interface is denoted as $\mathrm{r}$ and was found to be equal to $20 \mu \mathrm{m}$ while the peak height of the delaminated area, denoted as $\delta$, was found to be $0.7 \mu \mathrm{m}$. The stress graphs for region 2 are also shown in fig. 2 . In this region, the direction of diffusion induced stress is opposite to that of the compressive residual stress gradient however due to high compressive residual stress, the value of diffusion induced stress is very small. Therefore, high compressive residual stress can be treated as a major influential parameter in coating which results in interfacial delamination. Compressive residual stress $\sigma_{\mathrm{r}_{\mathrm{c}}}$ is represented in region 2 in fig. 2 as the only major influential parameter as,

$$
\sigma=\sigma_{\mathrm{r}_{\mathrm{c}}}+\sigma_{\mathrm{d}_{\mathrm{c}}} \approx \sigma_{\mathrm{r}_{\mathrm{c}}}
$$

The propagation of incipient interface crack (which is formed due to coating delamination) with increasing $\sigma$ can be explained by using normalised debonding driving force $F / G_{o}$. Therefore from fig. 2 , by using the experimental data values of $\sigma$ from region 2 and fitting them in to the normalised debonding driving force function: $\mathrm{F} / \mathrm{G}_{\mathrm{o}}=\mathrm{E}_{\mathrm{c}} \Gamma_{\mathrm{IC}} / \sigma^{2}\left(1-\mathrm{v}_{\mathrm{c}}\right) \mathrm{h}[60]$ gives an insight in to the profound influence of mode mix conditions on delamination behaviour as shown in fig. 4 . Where, $\mathrm{F}$ is the mode adjusted debonding driving force; mode I toughness $\Gamma_{\mathrm{IC}}$ appeared to depend on the thickness $\mathrm{h}$ of coating therefore, $\Gamma_{\mathrm{IC}} \approx 0.2 \mathrm{Jm}^{-2}$ for $\mathrm{h} \approx$ $20 \mu \mathrm{m}$ [61]. It can be seen in fig. 4 at zone $\mathrm{C}$, that as $\Delta \mathrm{T}$ was increased from $13 \mathrm{~K}, \mathrm{~F} / \mathrm{G}_{\mathrm{o}}$ started to increase rapidly which resulted in high rate of coating delamination until it reached maxima Max at $\Delta \mathrm{T}=23 \mathrm{~K}$. It is 
worth noting that $F / G_{0}$ only exists when the coating had already delaminated $(\Delta T \geq 13 \mathrm{~K})$ however in unbuckled state $(\Delta \mathrm{T}<13 \mathrm{~K})$ the debonding driving force is zero as shown in zones $\mathrm{A}$ and $\mathrm{B}$.

\subsubsection{Region 3}

The constantly rising $\Delta \mathrm{T}$ from $23 \mathrm{~K}$, from now onwards induced significantly high compressive residual stress which resulted in complete (visible) delamination of coating from the substrate. The constricted coating microcrack now in case of region 3, wide opened again after the formation of large dome shaped blister. The size of micro-crack aperture increased to $2.5 \mu \mathrm{m}$ (the blister size in image 1 (e) exceeds the image scale for current microscopic resolution, the measurement of aperture size is still made at $0.5 \mu \mathrm{m}$ depth from coating surface and is shown by dotted line) which was larger than the initial aperture size of micro-crack at the start of experiment. This behaviour of micro-crack opened the diffusion path for the corrosive species and resulted in high diffusion rate. The blister size due to high diffusion rate and diffusion induced stress eventually became very large and reached to a value of $\delta=5.2 \mu \mathrm{m}$ and $\mathrm{r}=35 \mu \mathrm{m}$ as shown in the cross sectional image fig. 1(e) and top view image 3 (e) (radius $r$ is shown with a dotted line as the blister size exceeds the image scale). The values of radius $\mathrm{r}$ and peak height $\delta$ of delaminated area were observed to be constantly increasing with the blister size and reached to value of $\mathrm{r}=75 \mu \mathrm{m}$ and $\delta=11.1 \mu \mathrm{m}$ as shown in cross sectional image fig. 1(f) and top view image 3 (f). It is worth noting that in region 3 , high diffusion rate resulted in the formation of corrosion products further reducing the fracture toughness. For this region, the diffusion rate was initially low and then increased with respect to increasing compressive residual stress, therefore, the direction of diffusion induced stress can be treated as identical to that of the compressive stress gradient. Both the diffusion induced stress and the compressive residual stress in coating were increasing as shown in region 3 in fig. 2 . The elastic response of coating in terms of the principle of linear superposition can be written as,

$$
\sigma=\sigma_{\mathbf{r}_{\mathrm{c}}}-\sigma_{\mathbf{d}_{\mathrm{c}}}
$$

The blister, after nucleation in region 3, had now propagated in stable circular pattern with increasing compressive residual stress and diffusion induced stress). For the stable circular growth of blister, $F / G_{0}$ (which was calculated by using the same previous relation i.e. $\left.F / G_{o}=E_{c} \Gamma_{I C} / \sigma^{2}\left(1-v_{c}\right) h\right)$ was seen to remain constant at zone $\mathrm{D}$ in fig. 4 except for the possible instability with respect to non-axisymmetric growth (which will be discussed in our forthcoming paper).

Based on these observations, a model has been developed to address the effect of micro-cracks on the initiation of blister and its propagation in circular symmetric pattern.

\section{Mathematical model}

The presented model couples the thermodynamic concepts involving the diffusion of corrosive species through micro-cracks with mechanics concepts incorporating a bi-layer cantilever beam theory. The previous model has been developed and reported in [62] which investigated the behaviour of micro-cracks under the effect of tensile residual stress causing the micro-cracks to open wide right from the start of region 1 resulting in high corrosion rate at the interface. However, for such analysis, electrochemistry concepts (describing interfacial corrosion) were incorporated within the thermodynamics and solid mechanics concepts forming a three-part approach.

In this research which includes the compressive residual stress effects on micro-cracks causing blistering, fracture mechanics concepts (instead of electrochemistry concepts) involving von Karman nonlinear plate theory were used. Some of the equations for thermodynamics are utilised from [62] to develop a new blistering model under compressive loading in the presence of micro-cracks. The integration of thermodynamics and mechanics concepts which form a two-part blistering approach is shown in fig. 5 (a-b). The thermodynamics part of fig. 5 (a) shows the varying size of micro-cracks opening (with increasing compressive stress) which affects the diffusion rate of species through the micro-cracks (portrayed by the arrows of various lengths) and 
diffusion induced stress. The mechanics part of fig. 5 (a) shows the propagation of circular blister as interfacial crack under the coupling effect of compressive and diffusion induced stresses. Fig. 5 (b) shows the direction of blister propagation in addition to blister radius $r$ and radial angle $\theta$.

In the thermodynamics part of model, consider a bilayer cantilever beam with one layer exposed to the diffusing species maintaining a concentration $\mathrm{c}_{\mathrm{o}}$ as shown in fig. 5 (a). Then according to current design, the top layer of the bilayer cantilever beam acts as a coating having a thickness $h$, length $l_{c}$ and width $b_{c}$ while the bottom layer of bilayer cantilever acts as a substrate having thickness $s$, length $l_{s}$ and width $b_{s}$ as shown in fig. 5 (a). The coordinate system defines the interface of coating and substrate at location $\mathrm{x}=0$; the free surface of coating and substrate are located at $\mathrm{x}=\mathrm{h}$ and $\mathrm{x}=-\mathrm{s}$ respectively.

The following assumptions have been used during the analyses (i) thickness in each layer of bilayer cantilever is small compared to its length (ii) material properties such as Young's modulus and coefficient of thermal expansion mismatch (CTE) of coating do not vary during position change, during deformation and diffusion (iii) planer section which is perpendicular to axis remains planer after bending (iv) strains and rotations are negligible.

The concentration of corrosive species within the stressed elastic coating (top layer) changes with respect to time, as given below. The equation has already been derived in detail in paper [62] (eq. 21 (a)).

$$
\frac{\partial \mathrm{c}_{\mathrm{k}_{\mathrm{c}}}}{\partial \mathrm{t}}=\left\{\left(\mathrm{D}_{\mathrm{k}_{c}}+\frac{\mathrm{D}_{\mathrm{k}_{c}} \mathrm{E}_{\mathrm{c}} \mathrm{V}_{\mathrm{k}_{\mathrm{c}}}^{2}}{9 \mathrm{RT}} \mathrm{c}_{\mathrm{k}_{\mathrm{c}}}\right) \frac{\partial^{2} \mathrm{c}_{\mathrm{k}_{\mathrm{c}}}}{\partial \mathrm{x}^{2}}+\frac{\mathrm{D}_{\mathrm{k}_{c}} \mathrm{E}_{\mathrm{c}} \mathrm{V}_{\mathrm{k}_{\mathrm{c}}}{ }^{2}}{9 \mathrm{RT}}\left(\frac{\partial \mathrm{c}_{\mathrm{k}}}{\partial \mathrm{x}}\right)^{2}-\frac{\mathrm{D}_{\mathrm{k}_{c}} \mathrm{~V}_{\mathrm{k}_{\mathrm{c}}}}{9 \mathrm{RT}} \frac{\partial \mathrm{c}_{k_{c}}}{\partial \mathrm{x}}\left(\frac{\partial \sigma_{\mathrm{r}_{\mathrm{c}}}}{\partial \mathrm{x}}-\frac{\partial \sigma_{\mathrm{d}_{\mathrm{c}}}}{\partial \mathrm{t}}\right)\right\}
$$

Where, $\partial \sigma_{\mathrm{r}_{\mathrm{c}}} / \partial \mathrm{x}$ is the change in resultant principle residual stresses along the surface of coating and $\frac{\partial \sigma_{\mathrm{d}_{\mathrm{c}}}}{\partial \mathrm{t}}$ is the change in principle diffusion induced stresses in coating with respect to time; $\mathrm{c}_{\mathrm{k}_{\mathrm{c}}}$ represents the concentration of species $\mathrm{k}$ in an infinitely diluted electrolyte solution while $\frac{\partial \mathrm{c}_{\mathrm{k}}}{\partial \mathrm{x}}$ represent the change in concentration along the surface of coating; $\mathrm{D}_{\mathrm{k}_{c}}$ is the diffusion coefficient of species $\mathrm{k}$ in coating; $\mathrm{R}$ represents the molar gas constant and $\mathrm{T}$ is the temperature; $\mathrm{V}_{\mathrm{k}_{\mathrm{c}}}$ is a scaler term, independent of stress, representing the partial molar volume of diffusing corrosive species $\mathrm{k} ; \mathrm{E}_{\mathrm{c}}$ is the elastic modulus of coating.

It should be noted that the first and the second terms on right hand side of the equation denote the chemical contribution without the stress effect inclusion while the third term represents the coupling relation of diffusion induced stress and residual stress. It is also worth noting that in the above equation, concentration per unit time $\partial \mathrm{c}_{\mathrm{k}} / \partial \mathrm{t}$ (or diffusion rate) is a function of resultant stress change $\frac{\partial \sigma_{\mathrm{r}_{\mathrm{c}}}}{\partial \mathrm{x}}-\frac{\partial \sigma_{\mathrm{d}_{\mathrm{c}}}}{\partial \mathrm{t}}$. Considering the material properties to be constant, the resultant stress change $\frac{\partial \sigma_{\mathrm{r}_{\mathrm{c}}}}{\partial \mathrm{x}}-\frac{\partial \sigma_{\mathrm{d}_{\mathrm{c}}}}{\partial \mathrm{t}}$ controls the diffusion rate of corrosive species through an elastic coating which depicts the behaviour similar to micro-cracks controlling the diffusion rate through coating under the resultant stress.

Eq. 6 can be modified to define a relation which represents the resultant stress change $\frac{\partial \sigma_{\mathrm{r}_{\mathrm{c}}}}{\partial \mathrm{x}}-\frac{\partial \sigma_{\mathrm{d}_{\mathrm{c}}}}{\partial \mathrm{t}}$ as a function of $\mathbf{c}_{\mathbf{k}_{\mathbf{c}}}, \frac{\partial \mathbf{c}_{\mathbf{k}_{\mathbf{c}}}}{\partial \mathrm{t}}, \frac{\partial \mathbf{c}_{\mathbf{k}_{\mathbf{c}}}}{\partial \mathrm{x}}$ and $\mathrm{V}_{\mathrm{k}_{\mathrm{c}}}$ as,

$$
\sigma=\frac{\partial \sigma_{\mathbf{r}_{c}}}{\partial x}-\frac{\partial \sigma_{d_{c}}}{\partial t}=\left(\left(9 R T+E_{c}{V_{k_{c}}}^{2} c_{k_{c}}\right) \frac{\partial^{2} c_{k_{c}}}{\partial x^{2}}+E_{c} V_{k_{c}}^{2}\left(\frac{\partial c_{k_{c}}}{\partial x}\right)^{2}-\frac{\partial c_{k_{c}}}{\partial t} 9 R_{T D_{k_{c}}}^{-1}\right)\left({V_{k_{c}}}^{2} \frac{\partial c_{k_{c}}}{\partial x}\right)^{-1}
$$

Eq. 7 for the resultant stress change $\sigma=\frac{\partial \sigma_{r_{c}}}{\partial x}-\frac{\partial \sigma_{d_{c}}}{\partial t}$ is analogous to eq. 5 in region 3 derived thorough experimental findings. The equation is of central interest, as region 3 is the only region which encounters blister nucleation and propagation, the focal point of this paper. Therefore, for the prediction of blister growth, eq. 7 can be employed to calculate the effect of resultant stress change $\sigma$ on the debondment crack tips which now integrates the previous thermodynamics concepts with the mechanics concepts. 
The debondment crack tip is formed as a result of incipient delamination of coating from substrate. The conventional form of normalised stress $\left(\frac{\boldsymbol{\sigma}}{\boldsymbol{\sigma}_{\mathbf{c r}}}=\mathbf{E}_{\mathbf{c}}^{-\mathbf{1}}\left(\mathbf{1}-\mathbf{v}_{\boldsymbol{c}}^{2}\right) \boldsymbol{\sigma}\left(\frac{\mathbf{r}}{\mathbf{h}}\right)^{2}[63]\right)$, can now be modified after incorporating eq. 7 as,

$$
\frac{\sigma}{\sigma_{c r}}=E_{c}^{-1}\left(1-v_{c}^{2}\right)\left(\left(9 R T+E_{c} V_{k_{c}}^{2} c_{k_{c}}\right) \frac{\partial^{2} c_{k_{c}}}{\partial x^{2}}+E_{c} V_{k_{c}}^{2}\left(\frac{\partial c_{k_{c}}}{\partial x}\right)^{2}-\frac{\partial c_{k_{c}}}{\partial t} 9 R_{T D_{k_{c}}}{ }^{-1}\right)\left({V_{k_{c}}}^{2} \frac{\partial c_{k_{c}}}{\partial x}\right)^{-1}\left(\frac{r}{h}\right)^{2} 8
$$

Where, $\mathrm{r}$ is the radius and represents the radius of a circular interface debondment (blister) as shown in fig. 5 (ab). A circular interface debondment exists between the coating and substrate; $\sigma_{\mathrm{cr}}$ is the critical stress when the coating just begins to delaminate from the substrate in both plane strain and axisymmetric mode [64]. $\sigma_{\mathrm{cr}}$ depends on the radius of circular interface crack between coating and substrate; larger debondment radius $r$ at the interface accounts for smaller $\sigma_{\mathrm{cr}}$ and vice versa. It is worth noting that $\sigma / \sigma_{\mathrm{cr}}$ in eq. 8 increases with the increase in resultant coating stress $\sigma$ as well as blister radius $r$. In this research, $\sigma$ is increasing in region 2 and 3 which results in the increase in $\mathrm{r}$ causing $\sigma / \sigma_{\mathrm{cr}}$ to increase.

The normalised driving force $F / G_{0}$ for debondment propagation is influenced by the elastic energy release rate $\mathrm{G}$ and a dimensionless mode mix function $\mathrm{f}(\psi),[65]$

$$
\begin{aligned}
& \frac{F}{G_{o}}=G\left(f(\Psi) G_{o}\right)^{-1}=\underset{9}{6\left(1-v_{c}^{2}\right)} \underset{9}{\left[M_{c}^{2}+\frac{1}{12} h^{2} \Delta N^{2}\right]}\left[h^{3} \sec ^{2}[(1-\lambda) \Psi]\left(1-v_{c}\right) h \sigma^{2}\right]^{-1} \\
& \psi=\frac{\mathrm{K}_{2}}{\mathrm{~K}_{1}}=\tan ^{-1} \frac{\cos \omega+\left[\frac{\mathrm{h} \Delta \mathrm{N}}{\sqrt{12} \mathrm{M}_{\mathrm{c}}}\right] \sin \omega}{\left[\frac{\mathrm{h} \Delta \mathrm{N}}{\sqrt{12} \mathrm{Mc}}\right] \cos \omega-\sin \omega} \\
& \mathrm{h} \Delta \mathrm{N} / \sqrt{12} \mathrm{M}_{\mathrm{c}}=0.2\left(1+\mathrm{v}_{\mathrm{c}}\right)\left(\frac{\delta}{h}\right) ; \quad \text { where } \frac{\delta}{h}=\left(\left(0.2\left(1+\mathrm{v}_{\mathrm{c}}\right)+0.2\left(1-\mathrm{v}_{\mathrm{c}}^{2}\right)\right)^{-1}\left(\frac{\sigma}{\sigma_{\mathrm{cr}}}-1\right)\right)^{\frac{1}{2}}
\end{aligned}
$$

Where, $G_{0}$ is the elastic energy per unit area stored in the coating which has not delaminated yet; $\psi$ defines the ratio of mode II to mode I for debondment crack edge; $\lambda$ (varies between 0 to 1 ) is the roughness parameter which is related to the roughness of the fractured interface with higher $\lambda$ (close to 1) accounting for lower interfacial roughness and vice versa, $\lambda$ for Primer coated steel substrate is found to be about 0.3 [66]; $M_{c}$ represents the bending moment of the crack edge as shown in fig. 5 (a); $\Delta \mathrm{N}$ is the resultant stress force acting on the coating; $\omega$ in eq. 9 (c) depends on elastic mismatch $\chi$ [67]. Where $\left.\chi=\left(\overline{\mathrm{E}_{\mathrm{c}}}-\overline{\mathrm{E}_{\mathrm{s}}}\right) / \overline{\left(\mathrm{E}_{\mathrm{c}}\right.}+\overline{\mathrm{E}_{\mathrm{s}}}\right)[68]$.

From eq. 9 and eq. 9 (a), it can be seen that G, f( $\psi)$ and $\psi$ at the edge of crack depend on the combination-terms $\mathrm{h} \Delta \mathrm{N} / \sqrt{12} \mathrm{M}_{\mathrm{c}}$ in eq. 9 (b), the term being the function of normalised blister height $\delta / h$. While $\delta / h$ is a function of normalised stress $\sigma / \sigma_{\mathrm{cr}}$. Above substitutions of eq. 9 (a-b) in to eq. 9 redefine the Hutchinson's delamination propagation problem [63] for $F / G_{0}$ in terms of resultant stress $\sigma$, which is a function of coupled residual and diffusion induced stresses.

\section{Results and discussion}

Based on the numerical simulation with the finite difference method, the effects of compressive residual stress coupled with diffusion induced stress on the nucleation and propagation of blister in the presence of micro-crack in coating are discussed in this section. For numerical work, all the dimensional parameters within the equations were normalised in the form as: Young's moduli ratio $\mathrm{E}_{\mathrm{c}} / \mathrm{E}_{\mathrm{s}}$, thickness ratio $\mathrm{h} / \mathrm{s}$, diffusion ratio $\mathrm{D}_{\mathrm{k}_{\mathrm{c}}} / \mathrm{D}_{\mathrm{k}_{\mathrm{s}}}$, partial molar volume ratio $\mathrm{V}_{\mathrm{k}_{\mathrm{c}}} / \mathrm{V}_{\mathrm{k}_{\mathrm{s}}}$, CTE mismatch ratio $\alpha_{\mathrm{c}} / \alpha_{\mathrm{s} \text {. }}$ and concentration ratio $\mathrm{c}_{\mathrm{k}_{\mathrm{c}}} / \mathrm{c}_{\mathrm{k}_{\mathrm{s}}}$. 
At first, the model prediction was validated by qualitative comparison with the experiment. The experiment showed a good qualitative agreement with the trend as predicted by the theory as shown in fig. 6 . The simulation result for the effect of increasing $\Delta \mathrm{T}$ on the normalised (mode adjusted) debonding driving force $\mathrm{F} / \mathrm{Go}$ is shown in fig. 6 where $\mathrm{D}_{\mathrm{k}_{\mathrm{c}}} / \mathrm{D}_{\mathrm{k}_{\mathrm{s}}}=10^{2}, \mathrm{~V}_{\mathrm{k}_{\mathrm{c}}} / \mathrm{V}_{\mathrm{k}_{\mathrm{s}}}=0.5, \lambda=0.3, \mathrm{~h} / \mathrm{s}=0.2, \alpha_{\mathrm{c}} / \alpha_{\mathrm{s}}=2, \mathrm{v}_{\mathrm{c}}=0.25$ and $\mathrm{E}_{\mathrm{c}} / \mathrm{E}_{\mathrm{s}}=0.03$. The plot shows that at $\Delta \mathrm{T}<13 \mathrm{~K}$ when the coating is intact with the substrate (blister radius $\mathrm{r}=0$ ) due to low resultant stress $\sigma$ in regions 1 and 2 at zones $\mathrm{A}$ and $\mathrm{B}$, the debonding driving force is zero. Only when the coating buckles away from the substrate $(\mathrm{r}>0)$ at $\Delta \mathrm{T}>13 \mathrm{~K}$ under high resultant stress $\sigma$, there is a non-zero debonding driving force at zones $\mathrm{C}$ and $\mathrm{D}$. The plot shows that after $\Delta \mathrm{T}=13 \mathrm{~K}$, the debonding driving force starts to increase because from this zone onwards the blister initiates and starts to spread. Further, above a certain value of $\Delta \mathrm{T}=$ $23 \mathrm{~K}$ when the resultant stress is very high, the debonding driving force $\mathrm{F}$ diminishes with increasing $\Delta \mathrm{T}$, considering $\lambda=0.3$. Therefore, a growing circular blister, in a state to the right of maxima Max is stable and grows in an axisymmetric circular pattern.

Effects of various values of coefficient of thermal expansion (CTE) mismatch $\alpha_{\mathrm{c}} / \alpha_{\mathrm{s}}$ on $\mathrm{F} / \mathrm{G}_{\mathrm{o}}$ are shown in fig. 7 , where $\mathrm{D}_{\mathrm{k}_{\mathrm{c}}} / \mathrm{D}_{\mathrm{k}_{\mathrm{s}}}=10^{2}, \mathrm{~V}_{\mathrm{k}_{\mathrm{c}}} / \mathrm{V}_{\mathrm{k}_{\mathrm{s}}}=0.5, \lambda=0.3, \mathrm{~h} / \mathrm{s}=0.2, \mathrm{v}_{\mathrm{c}}=0.25$ and $\mathrm{E}_{\mathrm{c}} / \mathrm{E}_{\mathrm{s}}=0.03$. From fig. 7, it is clear that as the CTE mismatch increases from $\alpha_{\mathrm{c}} / \alpha_{\mathrm{s}}=2$ to $\alpha_{\mathrm{c}} / \alpha_{\mathrm{s}}=8, \mathrm{~F} / \mathrm{G}_{\mathrm{o}}$ as a function of $\Delta \mathrm{T}$ also increases. For the case when $\alpha_{\mathrm{c}} / \alpha_{\mathrm{s}}=2, \mathrm{~F} / \mathrm{G}_{\mathrm{o}}$ initiates at $\Delta \mathrm{T}=13 \mathrm{~K}$ because from this zone onwards the blister nucleates and starts to spread. However, for the case when $\alpha_{\mathrm{c}} / \alpha_{\mathrm{s}}=4, \mathrm{~F} / \mathrm{G}_{\mathrm{o}}$ initialises at a lower $\Delta \mathrm{T}=11 \mathrm{~K}$. Similarly, for cases when $\alpha_{\mathrm{c}} / \alpha_{\mathrm{s}}=6$ and $\alpha_{\mathrm{c}} / \alpha_{\mathrm{s}}=8, \mathrm{~F} / \mathrm{G}_{\mathrm{o}}$ initiates at even lower values of $\Delta \mathrm{T}=9 \mathrm{~K}$ and $\Delta \mathrm{T}=7 \mathrm{~K}$ respectively compared to $\alpha_{\mathrm{c}} / \alpha_{\mathrm{s}}=4$. The reason for this early initiation of $\mathrm{F} / \mathrm{G}_{\mathrm{o}}$ is that the increasing $\alpha_{\mathrm{c}} / \alpha_{\mathrm{s}}$ accounts for increasing compressive residual stress $\sigma_{r_{c}}$ in the coating at a given $\Delta \mathrm{T}$. This behaviour due to increasing compressive residual stress corresponding to increasing $\alpha_{\mathrm{c}} / \alpha_{\mathrm{s}}$ results in the coating to buckle away from the substrate (delamination initiation) at lower values of $\Delta \mathrm{T}$ in region 2. Therefore, earlier delamination of coating at lower values of $\Delta \mathrm{T}$ due to higher compressive residual stress results in the pre-existing coating micro-crack to fully contract. Such behaviour of micro-cracks at a lower $\Delta \mathrm{T}$ eliminates the effect of diffusion induced stress on delamination in region 2 such that resultant stress $\sigma$ becomes equal to the critical stress $\sigma_{r_{c}}$ i.e. $\sigma \approx \sigma_{r_{c}}$. It is worth noting that the trends for $\alpha_{\mathrm{c}} / \alpha_{\mathrm{s}}=2,4,6$ and 8, all show similar behaviour in a way that they all become stable after $\Delta \mathrm{T}=23 \mathrm{~K}$ in region 3 where the effect of debonding driving force $\mathrm{F}$ diminishes.

Fig. 8 shows the evolution of $\mathrm{F} / \mathrm{G}_{\mathrm{o}}$ corresponding to various values of moduli ratio $\mathrm{E}_{\mathrm{c}} / \mathrm{E}_{\mathrm{s}}$. The parameters are set as $\mathrm{D}_{\mathrm{k}_{\mathrm{c}}} / \mathrm{D}_{\mathrm{k}_{\mathrm{s}}}=10^{2}, \mathrm{~V}_{\mathrm{k}_{\mathrm{c}}} / \mathrm{V}_{\mathrm{k}_{\mathrm{s}}}=0.5, \lambda=0.3, \mathrm{~h} / \mathrm{s}=0.2, \alpha_{\mathrm{c}} / \alpha_{\mathrm{s}}=2$ and $\mathrm{v}_{\mathrm{c}}=0.25$. It is clear from fig. 8 that $\mathrm{F} / \mathrm{G}_{\mathrm{o}}$ gradually increases with the increasing $\Delta \mathrm{T}$ and then stabilises for various values of moduli ratio $\mathrm{E}_{\mathrm{c}} / \mathrm{E}_{\mathrm{s}}$. It can be seen that $F / G_{o}$ increases with the decrease in moduli ratio $E_{c} / E_{s}$. This indicates that, for a given value of thickness $\mathrm{h} / \mathrm{s}$ and concentration of diffusing corrosive species, increasing the flexibility of coating (decreasing $E_{c}$ ) can significantly increase the debonding driving force $F$. It is also clear that in region $2, F / G_{o}$ initiates earlier at lower $\Delta \mathrm{T}$ for lower value of moduli ratio compared to higher value of moduli ratio. Therefore, in order to avoid early failure of coating at lower $\Delta \mathrm{T}$ due to blistering under high compressive residual stress, it will be better to use coating-substrate system with higher value of moduli ratio $\Delta \mathrm{T}$. By doing so, it is believed that the coating-substrate system can sustain high $\Delta \mathrm{T}$ without failing as seen for the case of $\mathrm{E}_{\mathrm{c}} / \mathrm{E}_{\mathrm{s}}=0.12$ in fig. 8 .

For the case, considering the total thickness of coating-substrate system to be constant, the effects of thickness ratio $\mathrm{h} / \mathrm{s}$ on $\mathrm{F} / \mathrm{G}_{\mathrm{o}}$ are shown in fig. 9 where, $\mathrm{D}_{\mathrm{k}_{\mathrm{c}}} / \mathrm{D}_{\mathrm{k}_{\mathrm{s}}}=10^{2}, \mathrm{~V}_{\mathrm{k}_{\mathrm{c}}} / \mathrm{V}_{\mathrm{k}_{\mathrm{s}}}=0.5, \lambda=0.3, \alpha_{\mathrm{c}} / \alpha_{\mathrm{s}}=2, \mathrm{v}_{\mathrm{c}}=0.25$ and $\mathrm{E}_{\mathrm{c}} / \mathrm{E}_{\mathrm{s}}=0.03$. From fig. 9 it is observed that $\mathrm{F} / \mathrm{G}_{\mathrm{o}}$ increases with increasing $\Delta \mathrm{T}$ for various values of $\mathrm{h} / \mathrm{s}$. It can be seen that as the value of $\mathrm{h} / \mathrm{s}$ increases, $\mathrm{F} / \mathrm{G}_{\mathrm{o}}$ decreases showing that the coating with larger thickness accounts for less failure probability due to blistering compared to coating with smaller thickness. It can also be seen in region 2 that as the value of $\mathrm{h} / \mathrm{s}$ increases, $\mathrm{F} / \mathrm{G}_{\mathrm{o}}$ initiates later at higher $\Delta \mathrm{T}$ as for the case of $\mathrm{h} / \mathrm{s}=0.5 \mathrm{in}$ fig. 9 . Therefore, in order to avoid early failure of coating-substrate system due to blistering under high compressive residual stress, higher value of $\mathrm{h} / \mathrm{s}$ should be used.

Fig. 10 shows the trends of $\mathrm{F} / \mathrm{G}_{\mathrm{o}}$ with increasing $\Delta \mathrm{T}$ for various values of coatings poisson's ratio $\mathrm{v}_{\mathrm{c}}$ where, $\mathrm{D}_{\mathrm{k}_{\mathrm{c}}} / \mathrm{D}_{\mathrm{k}_{\mathrm{s}}}=10^{2}, \mathrm{~V}_{\mathrm{k}_{\mathrm{c}}} / \mathrm{V}_{\mathrm{k}_{\mathrm{s}}}=0.5, \lambda=0.3, \mathrm{~h} / \mathrm{s}=0.2, \alpha_{\mathrm{c}} / \alpha_{\mathrm{s}}=2$ and $\mathrm{E}_{\mathrm{c}} / \mathrm{E}_{\mathrm{s}}=0.03$. It can be seen that $\mathrm{F} / \mathrm{G}_{\mathrm{o}}$ increases with the increase in value of $\mathrm{v}_{\mathrm{c}}$. It can also be observed, that the $\Delta \mathrm{T}$ at which $\mathrm{F} / \mathrm{G}_{\mathrm{o}}$ initialises for various values 
of $\mathrm{v}_{\mathrm{c}}$ in region 2 is irrespective of the value of $\mathrm{v}_{\mathrm{c}}$. Therefore, all the trends of $\mathrm{F} / \mathrm{G}_{\mathrm{o}}$ corresponding to various values of $\mathrm{v}_{\mathrm{c}}$ initiate at the same $\Delta \mathrm{T}=13 \mathrm{~K}$. However, all the trends of $\mathrm{F} / \mathrm{G}_{\mathrm{o}}$ after initiation from the same point on temperature scale in region 2 , now gradually increase with the increasing $\Delta \mathrm{T}$ and start showing distinct behaviour in terms of the magnitude of $\mathrm{F} / \mathrm{G}_{0}$ close to maxima Max. Therefore, in order to avoid high debonding driving force resulting in the coating failure, the value of coatings poisson's ratio should be kept small.

Fig. 11 illustrates the effect of various values of roughness parameter $\lambda$ on $F / \mathrm{G}_{\mathrm{o}}$ with increasing $\Delta \mathrm{T}$ where $\mathrm{D}_{\mathrm{k}_{\mathrm{c}}} / \mathrm{D}_{\mathrm{k}_{\mathrm{s}}}=10^{2}, \mathrm{~V}_{\mathrm{k}_{\mathrm{c}}} / \mathrm{V}_{\mathrm{k}_{\mathrm{s}}}=0.5, \mathrm{~h} / \mathrm{s}=0.2, \alpha_{\mathrm{c}} / \alpha_{\mathrm{s}}=2, \mathrm{v}_{\mathrm{c}}=0.25$ and $\mathrm{E}_{\mathrm{c}} / \mathrm{E}_{\mathrm{s}}=0.03$. It can be seen that $\mathrm{F} / \mathrm{G}_{\mathrm{o}}$ increases with the increase in $\lambda$ showing that the coating-substrate system will experience larger failure probability due to higher debonding driving force $\mathrm{F}$ when the interfacial roughness is small (high $\lambda$ close to 1 ). Similarly, the failure probability of coating-substrate system will be low when the interfacial roughness is high (low $\lambda$ close to 0 ). It can also be seen that the $\Delta T$ corresponding to which the debonding driving force $F / G_{0}$ initiates does not depend on the value of $\lambda$ therefore all the trends initiate at the same $\Delta \mathrm{T}=13 \mathrm{~K}$. However, after initiation in region 2 close to maxima Max, each trend of $F / G_{0}$ shows different behaviour in terms of the magnitude of $F / G_{0}$ in region 3 .

\section{Conclusions}

This paper presents blistering mechanism in the presence of coating micro-cracks under the influence of compressive residual and diffusion induced stresses. Initial experimental studies showed that the elastic response of coating depended on the residual stress and diffusion induced stress can be analysed in terms of the principle of linear superposition. Since, the CTE of red oxide primer coating is greater than the steel substrate i.e. $\alpha_{c}>\alpha_{s}$, the increasing temperature from fabrication temperature $(\Delta T>0)$ induces increasing compressive residual stress in the coating allowing the gradual contraction of pre-existing coating micro-cracks. This steady contraction of micro-cracks allows blocking of species diffusion towards the interface and therefore, reducing the diffusion induced stress in the coating while the compressive residual stress increases. To this point of increasing $\Delta \mathrm{T}$, the direction of diffusion induced stress can be treated as opposite to that of the compressive stress gradient. With further increase in temperature, the micro-cracks will reach to the point, where they cannot be constricted any further and high compressive residual stress will cause the coating to buckle away causing delamination and therefore initiating blistering. As the coating delaminates under high compressive residual stress, the micro-cracks wide open again and diffusion of corrosive species starts again therefore, increasing the diffusion induced stress in the coating. Hence the direction of diffusion induced stress can be treated as similar to that of the compressive stress gradient. The high resultant stress in coating causes the blister to propagate in an axis-symmetric circular pattern.

Based on the experimental observations a two-part theoretical approach has been utilised coupling thermodynamic concepts involving diffusion of corrosive species with mechanics concepts incorporating bilayer cantilever beam theory. The diffusion concept is used to treat the corrosive species transport through micro-cracks under increasing compression, eventually causing blistering, while the fracture mechanics concept is used to treat the blister growth as circular defect propagation. The simulation results show that larger CTE mismatch $\alpha_{c} / \alpha_{s}$ accounts for higher normalised debonding driving force $F / G_{0}$; therefore to achieve better performance of coating-substrate system, it is always better to use less CTE mismatch of coating and substrate. Higher modulus ratio $E_{s} / E_{c}$ accounts for lower $F / G_{o}$ therefore, keeping modulus ratio $E_{s} / E_{c}$ high can significantly improve the performance of coating-substrate system in terms of blistering. Larger thickness ratio $\mathrm{h} / \mathrm{s}$ accounts for lower $\mathrm{F} / \mathrm{G}_{\mathrm{o}}$ therefore, to achieve better performance of coating-substrate system, it is better to keep thickness ratio $\mathrm{h} / \mathrm{s}$ high. Larger poisson's ratio incurs lower $\mathrm{F} / \mathrm{G}_{\mathrm{o}}$ showing that for better performance of coating-substrate system in terms of blistering it will be better to select coating material with lower poisson's ratio. Interfacial roughness directly effects $F / G_{0}$, showing that larger interfacial roughness (smaller $\lambda$ close to 0 ) account for lower $F / G_{o}$ assuring better performance while smaller interfacial roughness (larger $\lambda$ close to 1 ) account for higher $\mathrm{F} / \mathrm{G}_{0}$. 
The prediction results were compared with the experimental results showing good quantitative and qualitative agreement between the two. The capabilities of theoretical model can be extended for predicting the unstable growth of circular blister, forming "telephone cord blister" which will be discussed in forthcoming research work.

\section{Acknowledgement}

The authors would like to acknowledge the financial support provided by the Defence Science and Technology Laboratory (DSTL) Ministry of Defence (MoD) UK and Bournemouth University UK for conducting this research.

\section{Reference}

[1] J. M. Pommersheim, T. Nguyen, and K. Hartzfeld, "Prediction of blistering in coating systems," in $A C S$ Symposium Series, 1998, pp. 137-150.

[2] T. Nguyen, J. Hubbard, and J. Pommersheim, "Unified model for the degradation of organic coatings on steel in a neutral electrolyte," JCT, Journal of coatings technology, vol. 68, pp. 45-56, 1996.

[3] M. Morcillo, "Soluble salts: their effect on premature degradation of anticorrosive paints," Progress in Organic Coatings, vol. 36, pp. 137-147, 1999.

[4] K. Holmberg and A. Mathews, "Coatings tribology: a concept, critical aspects and future directions," Thin Solid Films, vol. 253, pp. 173-178, 1994.

[5] M. Kaufman and J. Fink, "Evidence for localized ductile fracture in the "brittle" transgranular stress corrosion cracking of ductile FCC alloys," Acta Metallurgica, vol. 36, pp. 2213-2228, 1988.

[6] T. Magnin, R. Chieragatti, and R. Oltra, "Mechanism of brittle fracture in a ductile 316 alloy during stress corrosion," Acta Metallurgica Et Materialia, vol. 38, pp. 1313-1319, 1990.

[7] K. Sieradzki and R. Newman, "Stress-corrosion cracking," Journal of physics and chemistry of solids, vol. 48, pp. 1101-1113, 1987.

[8] W.-Y. Chu, J. Yao, and C.-M. Hsiao, "Stress corrosion cracking of austenitic stainless steel under compressive stress," Corrosion, vol. 40, pp. 302-306, 1984.

[9] X. Liu and G. Frankel, "Effects of compressive stress on localized corrosion in AA2024-T3," Corrosion science, vol. 48, pp. 3309-3329, 2006.

[10] D. S. Campbell, "in Handbook of Thin Film Technology (Maissel L I and Glang R New

York: McGraw-Hill) Chap. 12.," 1970.

[11] X. Feng, Y. Huang, and A. Rosakis, "On the Stoney formula for a thin film/substrate system with nonuniform substrate thickness," Journal of Applied Mechanics, vol. 74, pp. 1276-1281, 2007.

[12] S. Huang and X. Zhang, "Gradient residual stress induced elastic deformation of multilayer MEMS structures," Sensors and Actuators A: Physical, vol. 134, pp. 177-185, 2007.

[13] H. Soliman and A. Waheed, "Effect on differential thermal expansion coefficient on stresses generated in coating," Journal of Materials Science \& Technology(China)(USA), vol. 15, pp. 457-462, 1999.

[14] T. Clyne and S. Gill, "Residual stresses in thermal spray coatings and their effect on interfacial adhesion: a review of recent work," Journal of Thermal Spray Technology, vol. 5, pp. 401-418, 1996.

[15] S. Widjaja, A. M. Limarga, and T. H. Yip, "Modeling of residual stresses in a plasma-sprayed zirconia/alumina functionally graded-thermal barrier coating," Thin Solid Films, vol. 434, pp. 216-227, 2003.

[16] X. Zhang, B. Xu, H. Wang, and Y. Wu, "An analytical model for predicting thermal residual stresses in multilayer coating systems," Thin Solid Films, vol. 488, pp. 274-282, 2005.

[17] M. Wisnom, M. Gigliotti, N. Ersoy, M. Campbell, and K. Potter, "Mechanisms generating residual stresses and distortion during manufacture of polymer-matrix composite structures," Composites Part A: Applied Science and Manufacturing, vol. 37, pp. 522-529, 2006.

[18] P. Bansal, P. Shipway, and S. Leen, "Residual stresses in high-velocity oxy-fuel thermally sprayed coatings-Modelling the effect of particle velocity and temperature during the spraying process," Acta Materialia, vol. 55, pp. 5089-5101, 2007.

[19] M. S. Ahmed, P. Munroe, Z.-T. Jiang, X. Zhao, W. Rickard, Z.-f. Zhou, et al., "Corrosion behaviour of nanocomposite TiSiN coatings on steel substrates," Corrosion Science, vol. 53, pp. 3678-3687, 2011. 
[20] E. Busso, J. Lin, S. Sakurai, and M. Nakayama, "A mechanistic study of oxidation-induced degradation in a plasma-sprayed thermal barrier coating system.: Part I: model formulation," Acta Materialia, vol. 49, pp. 1515-1528, 2001.

[21] I. Spitsberg, D. Mumm, and A. Evans, "On the failure mechanisms of thermal barrier coatings with diffusion aluminide bond coatings," Materials Science and Engineering: A, vol. 394, pp. 176-191, 2005.

[22] Y. Ida, "Thermodynamic theory of nonhydrostatically stressed solid involving finite strain," Journal of Geophysical Research, vol. 74, pp. 3208-3218, 1969.

[23] F. Larché and J. Cahn, "A linear theory of thermochemical equilibrium of solids under stress," Acta Metallurgica, vol. 21, pp. 1051-1063, 1973.

[24] W. B. Kamb, "The thermodynamic theory of nonhydrostatically stressed solids," Journal of Geophysical Research, vol. 66, pp. 259-271, 1961.

[25] F. Larcht'e and J. Cahn, "The effect of self-stress on diffusion in solids," Acta Metallurgica, vol. 30, pp. $1835-1845,1982$.

[26] G. B. Stephenson, "Deformation during interdiffusion," Acta Metallurgica, vol. 36, pp. 2663-2683, 1988.

[27] Y. S. Podstrigach and P. Shevchuk, "Effect of surface layers on diffusion processes and the resulting stress state in solids," Soviet materials science: a transl. of Fiziko-khimicheskaya mekhanika materialov/Academy of Sciences of the Ukrainian SSR, vol. 3, pp. 420-426, 1968.

[28] Y. Prawoto, N. Kamsah, M. M. Yajid, and Z. Ahmad, "Energy density mechanics applied to coating blistering problems," Theoretical and Applied Fracture Mechanics, vol. 56, pp. 89-94, 2011.

[29] F. Yang and J. Li, "Diffusion-induced beam bending in hydrogen sensors," Journal of applied physics, vol. 93, pp. 9304-9309, 2003.

[30] A. I. Rusanov, "Surface thermodynamics revisited," Surface Science Reports, vol. 58, pp. 111-239, 2005.

[31] S.-S. Shao, F.-Z. Xuan, Z. Wang, and S.-T. Tu, "Stress in film/substrate system due to diffusion and thermal misfit effects," Journal of Physics D: Applied Physics, vol. 42, p. 175413, 2009.

[32] F.-Z. Xuan, S.-S. Shao, Z. Wang, and S.-T. Tu, "Influence of residual stress on diffusion-induced bending in bilayered microcantilever sensors," Thin Solid Films, vol. 518, pp. 4345-4350, 2010.

[33] S. Ho, C. Hillman, F. Lange, and Z. Suo, "Surface cracking in layers under biaxial, residual compressive stress," Journal of the American Ceramic Society, vol. 78, pp. 2353-2359, 1995.

[34] X. Zhao, P. Munroe, D. Habibi, and Z. Xie, "Roles of compressive residual stress in enhancing the corrosion resistance of nano nitride composite coatings on steel," Journal of Asian Ceramic Societies, vol. 1, pp. 86-94, 2013.

[35] F.-Z. Xuan, L.-Q. Cao, Z. Wang, and S.-T. Tu, "Mass transport in laser surface nitriding involving the effect of high temperature gradient: Simulation and experiment," Computational Materials Science, vol. 49, pp. 104-111, 2010.

[36] A. Saeed, Z. Khan, M. Clark, M. Nel, and R. Smith, "Non-destructive material characterisation and material loss evaluation in large historic military vehicles," Insight-Non-Destructive Testing and Condition Monitoring, vol. 53, pp. 382-386, 2011.

[37] A. Saeed, Z. A. Khan, M. Hadfield, and S. Davies, "Material Characterization and Real-Time Wear Evaluation of Pistons and Cylinder Liners of the Tiger 131 Military Tank," Tribology Transactions, vol. 56, pp. 637-644, 2013.

[38] A. Saeed, Z. A. Khan, and E. Montgomery, "Corrosion Damage Analysis and Material Characterization of Sherman and Centaur-The Historic Military Tanks," Materials Performance and Characterization, vol. 2, pp. 1-16, 2013.

[39] Z. A. Khan, P. Pashaei, R. S. Bajwa, M. H. Nazir, and M. Camak, "Fabrication and characterisation of electrodeposited and magnetron sputtered thin films," International Journal of Computational Methods \& Experimental Measurements (WIT Press), vol. [In Press], 2015.

[40] M. H. Nazir, Z. Khan, and K. Stokes, "Modelling of metal-coating delamination incorporating variable environmental parameters," Journal of Adhesion Science and Technology, vol. 29, pp. 392-423, 2014.

[41] M. H. Nazir, Z. A. Khan, and K. Stokes, "Optimisation of Interface Roughness and Coating Thickness to Maximise Coating-Substrate Adhesion - A Failure Prediction and Reliability Assessment Modelling," Journal of Adhesion Science and Technology, vol. 29, pp. 1415-1445, 2015.

[42] M. H. Nazir, Z. A. Khan, and K. Stokes, "A Holistic Mathematical Modelling and Simulation for Cathodic Delamination Mechanism - A Novel and an Efficient Approach," Journal of Adhesion Science and Technology, vol. [In Press], 2015.

[43] M. H. Nazir, Z. A. Khan, and K. Stokes, "A unified mathematical modelling and simulation for cathodic blistering mechanism incorporating diffusion and fracture mechanics concepts," Journal of Adhesion Science and Technology, vol. 29, pp. 1200-1228, 2015. 
[44] M. H. Nazir, Z. A. Khan, and K. Stokes, "Maximising the interfacial toughness of thin coatings and substrate through optimisation of defined parameters," International Journal of Computational Methods \& Experimental Measurements (WIT Press), vol. [In Press], 2015.

[45] Z. A. Khan, M. Grover, and M. H. Nazir, "The Implications of Wet and Dry Turning on the Surface Quality of EN8 Steel," in Transactions on Engineering Technologies, ed: Springer, 2015, pp. 413-423.

[46] Y. Prawoto and B. Dillon, "Failure analysis and life assessment of coating: the use of mixed mode stress intensity factors in coating and other surface engineering life assessment," Journal of failure analysis and prevention, vol. 12, pp. 190-197, 2012.

[47] A. Volinsky, N. Moody, and W. Gerberich, "Interfacial toughness measurements for thin films on substrates," Acta materialia, vol. 50, pp. 441-466, 2002.

[48] H. Jahnsen, "Delamination of coatings," Handbook of Materials behavior models, pp. 582-6, 2001.

[49] M. Kappes, G. Frankel, and N. Sridhar, "Adhesion and adhesion degradation of a pressure sensitive tape on carbon steel," Progress in Organic Coatings, vol. 69, pp. 57-62, 2010.

[50] R. E. Galindo, A. Van Veen, J. Evans, H. Schut, and J. T. M. De Hosson, "A modified blister test to study the adhesion of thin coatings based on local helium ion implantation," Thin Solid Films, vol. 471, pp. 170-176, 2005.

[51] J. Bressers, S. Peteves, and M. Steen, "Coatings for hot section gas turbine components," European Structural Integrity Society, vol. 26, pp. 115-134, 2000.

[52] K.-t. Wan and K. Liao, "Measuring mechanical properties of thin flexible films by a shaft-loaded blister test," Thin Solid Films, vol. 352, pp. 167-172, 1999.

[53] D. R. Lide, CRC handbook of chemistry and physics: CRC press, Boca Raton, USA, 2004.

[54] https://www.rawlinspaints.com/index.php? controller=attachment\&id attachment=546.

[55] R. Delmelle, G. Bamba, and J. Proost, "In-situ monitoring of hydride formation in Pd thin film systems," international journal of hydrogen energy, vol. 35, pp. 9888-9892, 2010.

[56] F. Tian, J. H. Pei, D. L. Hedden, G. M. Brown, and T. Thundat, "Observation of the surface stress induced in microcantilevers by electrochemical redox processes," Ultramicroscopy, vol. 100, pp. 217223, 8// 2004.

[57] C.-H. Hsueh, "Modeling of elastic deformation of multilayers due to residual stresses and external bending," Journal of Applied Physics, vol. 91, pp. 9652-9656, 2002.

[58] Z.-X. Gui, K. Wang, Y.-S. Zhang, and B. Zhu, "Cracking and interfacial debonding of the Al-Si coating in hot stamping of pre-coated boron steel," Applied Surface Science, vol. 316, pp. 595-603, $10 / 15 / 2014$.

[59] W. Wilson and I.-W. Yu, "The use of the J-integral in thermal stress crack problems," International Journal of Fracture, vol. 15, pp. 377-387, 1979.

[60] A. G. Evans, D. Mumm, J. Hutchinson, G. Meier, and F. Pettit, "Mechanisms controlling the durability of thermal barrier coatings," Progress in materials science, vol. 46, pp. 505-553, 2001.

[61] Y. Huang, H. Gao, W. Nix, and J. Hutchinson, "Mechanism-based strain gradient plasticity-II. Analysis," Journal of the Mechanics and Physics of Solids, vol. 48, pp. 99-128, 2000.

[62] M. Nazir, Z. Khan, A. Saeed, and K. Stokes, "Modelling the Effect of Residual and Diffusion induced Stresses on Corrosion at the Interface of Coating and Substrate," Corrosion, 2015.

[63] J. Hutchinson, M. Thouless, and E. Liniger, "Growth and configurational stability of circular, bucklingdriven film delaminations," Acta metallurgica et materialia, vol. 40, pp. 295-308, 1992.

[64] T. Q. Lu, W. X. Zhang, and T. Wang, "The surface effect on the strain energy release rate of buckling delamination in thin film-substrate systems," International Journal of Engineering Science, vol. 49, pp. 967-975, 2011.

[65] L. Yao, R. Alderliesten, M. Zhao, and R. Benedictus, "Discussion on the use of the strain energy release rate for fatigue delamination characterization," Composites Part A: Applied Science and Manufacturing, vol. 66, pp. 65-72, 2014.

[66] J. W. Hutchinson, M. Mear, and J. R. Rice, "Crack paralleling an interface between dissimilar materials," Journal of Applied Mechanics, vol. 54, pp. 828-832, 1987.

[67] J. W. Hutchinson, "Mixed mode fracture mechanics of interfaces," Metal and Ceramic interfaces, pp. 295-306, 1990.

[68] S. Schmauder and M. Meyer, "Correlation between Dundurs' parameters and elastic constants," Zeitschrift für Metallkunde, vol. 83, pp. 524-527, 1992. 